\title{
El G20 y la remodelación financiera más allá de 2009. Legitimación y retos del nuevo diseño institucional para el desarrollo*
}

\section{G20 and the Financial Remodeling Beyond 2009. Legitimation and Challenges of the New Institutional Design for Development}

\section{David Enríquez**}

\begin{abstract}
Sumario: I. Aproximación. II. Las instituciones del Sistema Bretton Woods de 1944 y el camino del G20 hacia su transformación tras la crisis financiera de 2009. III. Las instituciones financieras del Sistema Bretton Woods: el Fondo Monetario Internacional y el Banco Mundial. IV. La crisis financiera internacional de 2009 y los primeros bocetos del G20 en la arquitectura del sistema financiero internacional. V. El Panel de Inspección del BM - una asignatura pendiente del G20 en la remodelación del sistema financiero internacional del siglo XXI. VI. Conclusiones.
\end{abstract}

* Artículo recibido el 23 de febrero de 2011 y aprobado para publicación el 28 de septiembre de 2011

** Doctor en derecho; profesor e investigador en el ITAM; socio en Goodrich, Riquelme. México. 
Resumen: El artículo estudia el papel que el G20 tiene en el nuevo diseño institucional del Fondo Monetario Internacional y del Banco Mundial tras la crisis financiera 2008-2009. A partir de una breve revisión histórica relativa a la creación del Sistema Bretton Woods, así como de las funciones de ambas instituciones financieras, el documento da cuenta de los avances en la agenda del G20 en el diseño organizacional, y distingue algunos de los principales retos en tal ejercicio. La hipótesis de trabajo del autor se centra en que, si bien el G20 tiene una innegable representatividad mundial, su legitimación en el rediseño institucional del sistema financiero multilateral solamente puede darse a partir de una efectiva democratización de las instituciones y de sus objetivos; los cuales se basan en las recomendaciones de la Comisión para el Análisis del Desarrollo Económico y el Progreso Social, creada en la primavera de 2008 a iniciativa del gobierno francés.

Palabras clave: G20, FMI, BM, sistema financiero internacional, crisis financiera

ABSTRACT:The article examines the role that the G2O has in the new institutional design of the International Monetary Fund andWorld Bank following the 2008-2009 financial crisis. After a brief historical review on the creation of the Bretton Woods institutions, as well as the roles of the two financial institutions, the document reports the progress on the G2O agenda in organizational design and identifies some major challenges in such exercise. The hypothesis of the author focuses on the undeniability of the G2O global representation, but its legitimacy in the institutional redesign of the multilateral financial system can only be given after the effective democratization of institutions and their objectives, based these, on the recommendations of the Commission for the Analysis of Economic and Social Progress, created in spring 2008 at the initiative of the French government.

Descriptors: G20, IMF,WB, International Financial System, Financial Crisis.

RÉSUMÉ: L'article examine le rôle que le G20 a dans le nouveau design institutionnel du Fonds Monétaire International et de la Banque Mondiale après la crise financière de 2008-2009. En partant d'une recension historique sur la création du Système Bretton Woods, ainsi que les fonctions des deux institutions financières, le document montre les progrès sur l'agenda du G2O dans le design organisationnel et il identifie certains de principales menaces dans cet exercice. L'hypothèse de l'auteur se concentre sur le caractère indéniable de la représentation du G20 mondiale, sa légitimité dans la refonte institutionnelle du système financier multilatéral, seulement elle peut être donnée après la démocratisation effective des institutions et de leurs objectifs, fondés ceux, sur les recommandations de la pour la Mesure des Performances Economiques et du Progrès Social créée au printemps 2008 à l'initiative du gouvernement français.

Mots-clés: G20; FMI; Banque Mondiale; Système Financier International; La Crise Financière. 


\section{APROXIMACIÓN}

La crisis financiera 2008-2009 ha producido amargas lecciones y oportunidades de cambio que deben ser encauzadas por los principales líderes del mundo, en buena medida, congregados, como en adelante analizaremos, en el G20.

Tal vez la mejor sistematización de las lecciones de la crisis ha sido el Reporte de la Comisión para el Análisis del Desarrollo Económico y el Progreso Social (la Comisión), creada por iniciativa del gobierno francés en la primavera de 2008. La Comisión ha sido coordinada por tres de los más prominentes economistas contemporáneos: Joseph Stiglitz, Amartya Sen y Jean-Paul Fitoussi. ${ }^{1}$ Como seguramente demostrará la historia del siglo XXI, el rol de estos intelectuales está llamado a tener un peso específico equivalente al que en su momento tuviera el pensamiento de J. Keynes en la década de los cuarenta.

Pues bien, a través de un análisis de fondo, formulado por algunos de los mejores científicos sociales de la historia reciente, congregados en tres grupos de trabajo, la Comisión ha concretado su labor en una docena de recomendaciones a ser valoradas por los líderes del mundo; particularmente por el G20. Así pues, el liderazgo del G20 no simplemente puede basarse en su representatividad, si no en la valoración profunda e implementación de esas y otras recomendaciones complementarias.

Si bien no es objeto de este documento analizar cada una de las recomendaciones, conviene identificarlas como las coordenadas a partir de las cuales el G20 debe ahondar, entre otros aspectos, en el rediseño de las instituciones financieras multilaterales, particularmente el Fondo Monetario Internacional y el Banco Mundial.

La síntesis de las doce recomendaciones es: (i) cuando se evalúe el bienestar material, tomar en cuenta el ingreso y el consumo, en lugar de la producción; (ii) poner énfasis en la perspectiva del hogar; (iii) considerar el ingreso y el consumo de modo conjunto con la riqueza; (iv) dar mayor prominencia a la distribución del ingreso, el consumo y la riqueza; (v) profundizar las medidas relacionadas con el ingreso

\footnotetext{
1 Véase el documento completo, así como otros trabajos complementarios y entrevistas a los coordinadores (visita a junio de 2011) en www.stiglitz-sen-fitoussi.fr.
} 
hacia actividades distintas a las de mercado; (vi) considerar que la calidad de vida depende de las condiciones objetivas y las capacidades de las personas; (vii) los indicadores de calidad de vida deben analizar la inequidad de modo integral; (viii) el monitoreo debe diseñarse para medir los vínculos entre los distintos aspectos de calidad de vida de cada persona; (ix) las entidades de estadística deben proveer la información necesaria para agregar las dimensiones de calidad de vida, para con ello construir diversos indicadores; (x) las entidades de estadística deben incorporar la evaluación de la gente sobre su vida, experiencias y prioridades; (xi) el análisis de sustentabilidad requiere un bien identificado "tablero" de indicadores a construir; (xii) los aspectos ambientales de la sustentabilidad merecen un seguimiento separado, basado en una buena selección de indicadores físicos.

Desde luego, la anterior síntesis es solamente enunciativa del profundo análisis que la Comisión llevó a cabo para sugerir los ejes para un cambio de derrotero de la economía mundial. El mensaje esencial puede en cierto sentido formularse en una expresión mínima: la economía mundial no está funcionando como podría, y solamente a partir de una revisión de fondo, los cambios que se implementen por el G20 serán eficaces. Es por ello que el Reporte de la Comisión debe ser una fuente de inspiración en el camino que el G20 ha iniciado.

En tal contexto, como ya hemos sugerido, una de las lecciones también aprendidas a partir de la crisis financiera es la urgente necesidad de rediseñar las instituciones financieras multilaterales, con miras a democratizar sus decisiones y lograr que sus fines y procesos se acerquen a las sugerencias de la Comisión. Ante tal oportunidad, ha sido a partir de los buenos oficios canadienses y alemanes que la comunidad internacional ha encontrado en el G20 el foro idóneo para discutir e implementar semejante reto.

Si bien la representatividad mundial del G20 es notoria $-85 \%$ del PIB, 80\% del comercio y 2/3 partes de la población — su legitimación para la tarea no es necesariamente de origen, sino de ejercicio. Esto es, el cambio efectivo en los organismos financieros multilaterales dependerá de la voluntad real del G20 expresada en acciones específicas de democratización y de un nuevo foco en los objetivos del sistema financiero internacional a partir de las recomendaciones de la Comisión. 
En este contexto y con tal hipótesis de trabajo, el objeto de este documento es examinar en perspectiva histórica, el nacimiento de las instituciones financieras multilaterales — principalmente el Fondo Monetario Internacional y el Banco Mundial - en el seno del Sistema Bretton Woods de 1944. A partir de ello, se pretende revisar las principales funciones de ambas entidades, así como profundizar en algunas de las tareas más emblemáticas en el ámbito del financiamiento para el desarrollo. Ello bajo el matiz de las obligaciones de derechos humanos que Estados y organismos internacionales tienen en el ámbito del desarrollo.

Con el fin de ahondar en los elementos de la hipótesis de trabajo, se estudian algunos aspectos relevantes de estructura, organización y políticas públicas en el ámbito del financiamiento para el desarrollo del BM, así como la necesidad de optimizar el rol del Panel de Inspección del propio BM, como uno de los cauces de democratización y transparencia que el G20 debe propiciar en su camino por implementar las sugerencias de la Comisión.

\section{LAS INSTITUCIONES DEL SiSTEMA BRETTON WOODS DE 1944 Y EL CAMINO DEL G20 HACIA SU TRANSFORMACIÓN TRAS LA CRISIS FINANCIERA DE 2009}

\section{Contexto histórico}

Hace más de sesenta años en Bretton Woods, New Hampshire, Estados Unidos, los delegados de cuarenta y cuatro países llegaron a un acuerdo sobre el marco institucional que la cooperación económica habría de seguir tras la finalización de la Segunda Guerra Mundial. Para bien o para mal, de la Conferencia Monetaria y Financiera de la Organización de las Naciones Unidas (ONU) reunida en Bretton Woods surgieron los cimientos de los ámbitos financiero y de desarrollo - así como, posteriormente el comercial — que conforman la columna vertebral del Derecho Internacional Económico (DIE). ${ }^{2}$

\footnotetext{
2 Véase, en general, Enríquez, David, Derecho internacional económico, México, Porrúa, 2006, pp. 153 y ss.; BWC, Bretton Woods: looking to the future, Comisión Report, Staff Review
} 
Si bien la economía internacional ha cambiado substancialmente desde la Conferencia en New Hampshire, instituciones globales como el Banco Mundial (BM), el Fondo Monetario Internacional (FMI), el Programa de las Naciones Unidas para el Desarrollo (PNUD) y la Organización Mundial del Comercio (OMC) — entre otras - no podrían ser entendidas hoy sin el complejo entorno conceptual y práctico debatido en ese entonces.

Desde nuestra perspectiva, la Conferencia de Bretton Woods de 1944 tiene dos grandes significados: representa por una parte, la cúspide conceptual de un proceso intelectual por institucionalizar ciertos factores clave de la economía mundial, y, por la otra, el arranque - con un alto nivel de control de Estados Unidos y otros países desarrollados - a distinta velocidad, de los acuerdos sobre el sistema económico alcanzados durante la posguerra. En estos párrafos trataremos de centrarnos en el primer significado, para más adelante adentrarnos en algunas de las instituciones mismas y la crítica a su organización y trabajo, desde una óptica plural.

Como explica H. Singer, aunque los orígenes del Bretton Woods suelen remontarse a Londres en 1942, con la elaboración y presentación por J. Keynes de sus estudios sobre reconstrucción europea, lo cierto es que para contar una perspectiva histórica más certera conviene dar unos pasos hacia atrás y centrarse a inicios de la década de los treinta.

Como es hoy evidente, la Gran Depresión iniciada en 1929 demostró que ante la ausencia de instrumentos multilaterales e instituciones internacionales, el sistema económico se enfrentaba al peligro de degenerar en aislacionismos y nacionalismos. La Conferencia Económica Mundial de 1931 fue el primer esfuerzo por crear un nuevo orden económico internacional que pudiera prevenir tal situación. ${ }^{3}$

Aunque la Conferencia de 1931 resultó un fracaso por su falta de consistencia y compromiso, su espíritu reafirmó la convicción del economista J. Keynes en diseñar los mecanismos necesarios para nunca más volver a las condiciones de los años treinta, que no sólo produjeron un

and Background Papers, NH, EE.UU, 1994; Ul Haq, M. et al., The UN and the Bretton Woods Institutions. New Challenges for the $21^{\text {st }}$ century, Nueva York, St. Martin's Press.

3 Singer, H., en UL, M. et al., The UN and the Bretton Woods institutions, Nueva York, Editorial SMP, 2001, p. 17. 
enorme desempleo y una lacerante miseria, sino que, peor aún, dieron lugar a la construcción del nazismo, y con él a la guerra de mayor escala de la historia de la humanidad. ${ }^{4}$

En efecto, la circunstancia histórica que formalmente detonó los influyentes reportes de J. Keynes — y que más tarde culminarían en la negociación de Bretton Woods - fue la honda preocupación del gobierno británico, cuando el ministro de Economía del gobierno nazi proclamó en 1940 un nuevo orden unificado a partir del supuesto liderazgo alemán.

Ante esa real amenaza, y a petición del Ministerio de Información del Reino Unido, la misión de Keynes consistía en preparar la defensa conceptual para desacreditar los contenidos económicos de este anunciado orden económico nazi. Sin embargo, Keynes fue mucho más allá de la solicitud británica, y articuló así los elementos clave de lo que intentaba ser un auténtico nuevo sistema económico internacional, cuyos resultados, pueden ser sólo parcialmente vistos en la negociación y los resultados de la Conferencia de Bretton Woods de 1944. En estas líneas no profundizaremos en los procedimientos de la Conferencia, sino en los pilares conceptuales que mediante ella intentaron ser instrumentados.

Será la historia del siglo XXI la que, en perspectiva comparativa con Bretton Woods, evaluará las recomendaciones de la Comisión creada a partir de la crisis financiera 2008-2009. En ese sentido, Stiglitz, Sen y Fitoussi serán — como lo fue Keynes — dimensionados en su justo valor. Más aún, el liderazgo mundial del G20 será sujeto de análisis, como en su momento lo fueron los líderes de la posguerra.

\section{El pensamiento keynesiano y el Sistema Bretton Woods}

La propuesta de Keynes para nunca más generar un ambiente crítico como el de la década de los treinta estaba fundamentada en su — posteriormente controvertida - persuasión por lograr un estadio económico permanente de empleo total, a través de una política gubernamental activa que fomentara el crecimiento de la economía mundial. La

4 Véase, en general, Keynes, John, The collected writings of John Maynard Keynes, Londres, MacMillan, 1971; Klein, R., The Keynesian Revolution, Londres, MacMillan, 1968; Pigou, A., Capitalismo y socialismo comparados, Barcelona, Ariel, 1968; Sacristán, A., Keynes ante la Crisis Mundial de los Ochenta, México, Siglo XXI, 1985. 
propuesta, hecha pública integralmente en 1942, bajo la forma de un conjunto de memorandos económicos — que a su vez se relacionaban con estudios académicos previos_-, se sostenía en lo que hoy podemos recapitular como cuatro columnas estructurales.

En este contexto, como veremos, la primera columna representa el proyecto general del sistema económico a establecer, mientras que las otras tres pretenden concretar los rasgos institucionales de aquél. Así, tenemos: (i) la sistematización de la gestión global de los asuntos monetarios y financieros macroeconómicos; (ii) la institucionalización de los fondos mediante lo que hoy conocemos como el BM y el FMI; (iii) la institucionalización de mecanismos para la estabilización de precios de ciertos insumos básicos de uso global que, tras cierto tiempo y muchas adecuaciones, se convertiría en la actual OMC, y (iv) la institucionalización de la asistencia y la cooperación técnica, mediante lo que más tarde aparecería como el PNUD. ${ }^{5}$

La sistematización de la gestión global de los asuntos monetarios y financieros en la macroeconomía - como primer pilar-contenía, a su vez, un par de elementos integradores. El primero consistía en dar forma a un verdadero banco central mundial que mantuviera el equilibrio del empleo total con crecimiento económico, y que proveyera de la liquidez requerida para ese objeto, mediante el suministro de una moneda mundial unificada - los bancors-.

El propósito básico se centraba en financiar a las naciones cuya balanza de pagos fuera deficitaria en virtud de haber generado el empleo neto adicional en el resto del mundo. ${ }^{6} \mathrm{El}$ segundo elemento se basaba en la constitución de un fondo financiero internacional que como contrapeso operativo tuviera una serie de requerimientos crediticios de orden macroeconómico.

5 V'ease UL, M., "The vision and the reality", The UN and the Bretton Woods, cit., p. 26.

6 Si bien no es el objeto de nuestro trabajo explicar con detalle la teoría económica keynesiana, debe tenerse en cuenta que en ella, y por consecuencia en su propuesta, los países que gozaran de un superávit en su balanza de pagos por "exportar" desempleo al resto del mundo, deberían pagar un impuesto de un 1\% sobre tal superávit. El impuesto sería utilizado por el banco en parte para financiar los déficits, en parte para financiar ciertos mercados de productos básicos de uso internacional, y en parte para incentivar a los países superavitarios para reducir sus superávits mediante la aplicación de políticas económicas más expansivas. La idea del crecimiento con empleo total sería desarrollada a partir de Keynes por Harrod y Domar. 
A pesar de que Keynes propuso originalmente un fondo realmente robusto - equivalente a la mitad de las importaciones mundiales de un año- y un régimen de condicionalidad moderado; resulta interesante caer en cuenta que, a la fecha, el FMI fondea un nivel mínimo de lo inicialmente pensado, y los requerimientos crediticios sobre condicionalidad son estrictos y en ocasiones violatorios de obligaciones internacionales en otras materias de regulación convencional.

A partir de la sistematización para administrar los asuntos monetarios y financieros, el segundo pilar diseñado por Keynes consistió en lograr la institucionalización efectiva de recursos. El primer paso en esta idea consistió en el Fondo de Reconstrucción Europeo, el cual hacia 1942 había ya evolucionado hacia un mecanismo de inversión y reconstrucción más general.

A raíz del Plan Marshall, de una serie de créditos a gran escala de EE.UU. al Reino Unido y otros países europeos, así como de una serie de circunstancias económicas relativamente positivas de otros países potencialmente acreditados _ principalmente latinoamericanos_-, la institucionalización de los recursos trascendió los aspectos propios de la reconstrucción europea, y se concretó a través del FMI y del BM.

La tercera columna responde al reiterado interés de Keynes en lograr la estabilización de los precios de ciertos productos e insumos básicos de uso internacional. Originalmente, la propuesta incluía la creación de una moneda mundial que no estuviera basada en el dólar, el oro, el sugerido bancor o los derechos especiales de giro, sino en el precio promedio de treinta mercancías básicas (incluidas el petróleo y el oro).

La porción del pensamiento económico de Keynes que trascendió como propuesta efectiva en este renglón fue la constitución de la llamada Organización Internacional del Comercio (OIC), cuyos objetivos serían la estabilización de precios mediante acuerdos comerciales sobre ciertos productos, intervención directa en los mercados y reservas de contención de productos específicos. La OIC, sin embargo, no vio nunca la luz, en buena medida por circunstancias políticas de Estados Unidos, que generaron un fuerte cuestionamiento en ese país a la viabilidad de la ONU y las organizaciones internacionales en general. ${ }^{7}$

\footnotetext{
7 Tras estudiar los factores que contribuyeron a la Gran Depresión iniciada en 1929, Keynes concluyó que era imperativo establecer un mecanismo efectivo que pudiera evitar un
} 
En este contexto, como acertadamente apunta H. Singer, el Sistema del Bretton Woods estaba incompleto desde su inicio, a falta de su tercera columna largamente proyectada. En nuestra opinión, aunado a lo anterior, habría que señalar que si bien es cierto que técnicamente el GATT no pudo llenar ese espacio vacante, simplemente por no tener funciones relativas a la estabilización de precios o regulación de mercados, también lo es que la actual OMC parece haber favorecido, aunque sólo relativamente, la ordenación de ciertos mercados. Con ello, en medio de controversias y críticas desde distintas perspectivas, parece también estar contribuyendo a la actual estabilidad de los precios objeto de sus bienes regulados, mediante mecanismos de liberalización y resolución de conflictos comerciales entre Estados miembros. ${ }^{8}$

El cuarto y último pilar de la propuesta de J. Keynes para la creación de un nuevo sistema económico mundial consistió en un fondo internacional para el desarrollo. La idea original era que este fondo fuera administrado en su totalidad por la ONU, a través de lo que se denominaría Fondo de las Naciones Unidas para el Desarrollo Económico.

Sin embargo, al igual que la OIC, el fondo estuvo desde su inicio condenado al fracaso por la hostilidad estadounidense a los organismos internacionales, principalmente durante la década de los cincuenta. Con ello, desde inicios de los sesenta, la ONU mantuvo solamente una porción poco significativa de los recursos financieros para el desarrollo económico y la asistencia social en materia alimenticia, a través de lo que hoy conocemos como el PNUD y la Organización de las Naciones Unidas para la Agricultura y la Alimentación (FAO).

Como podrá advertirse hasta aquí, la congruencia en la articulación económica — se esté o no de acuerdo con ella - y las buenas intenciones de J. Keynes y otros especialistas por crear un sistema económico fuerte y solidario no fueron suficientes. Más todavía, casi dos décadas de ensayos por institucionalizar la economía mundial con un rostro humano no parecen haber arribado al mejor puerto gracias a la dinámica de

nuevo colapso en el precio de las mercancías; a partir ello acuñó este tercer pilar de su propuesta. La inquietud del autor puede verse, sin embargo, reflejada desde varios años antes. Véase Keynes, J., “The policy of Government Storage of Food Stuffs and Raw Materials”, The Economic Journal, Londres, 1938.

8 Singer, H., op cit., p. 22. 
las relaciones internacionales. Es por ello que el escrutinio que la sociedad civil haga del actual trabajo de aparente remodelación que el G20 practica, debe demandar amplitud de miras y concreción de objetivos.

Es claro que el Bretton Woods generó, prácticamente para la posteridad, dos clases de instituciones — las duras y las débiles_-, entendiendo al BM, al FMI y a la OMC en las primeras, y al UNDP y entidades técnicas relacionadas a él en la segunda clase. ${ }^{9}$

Las primeras son titulares de instrumentos de hard law y de los recursos financieros públicos de disposición internacional más cuantiosos del mundo. Las segundas, en cambio, son entidades propias del soft law y, a pesar de sus mayúsculos requerimientos de capital para aliviar la pobreza en el mundo, reciben sólo una mínima porción de recursos internacionales. Una de las ironías sobre esta dicotomía es que unas y otras tienen cierto nivel de adscripción al Sistema de la ONU de acuerdo a sus tratados constitutivos e instrumentos fundacionales relacionados. ¿Es sostenible que este diseño institucional se mantenga tras las lecciones de la crisis de 2008-2009, y con ello, se perpetúe la inconsistencia del sistema basada en la falta de solidaridad humana?

En la práctica, como veremos, las primeras — de modo especial el BM y el FMI — han sido diseñadas de tal modo, que solamente ciertos países desarrollados — principalmente Estados Unidos — están facultados para decidir su destino, y con él, el de millones de personas en todo el mundo. En párrafos siguientes valoraremos la eficacia —o falta de ella_- del G20 en cuanto a la remodelación de estas instituciones.

III. LAS INSTITUCIONES FINANCIERAS DEL SISTEMA BRETTON WOODS: EL Fondo MONETARio InTERnaCiOnAL Y EL BANCO MUNDiAL

\section{Ideas generales}

Como ya hemos adelantado a lo largo de este trabajo, el análisis de cada ámbito temático del DIE — como disciplina que sistematiza el estu-

9 Véase Singer, H., "The Terms of Trade Controversy and the Evolution of Soft Financing: Early Years in the U.N.”, en Meier, G. y Dudley, S., Pioneers in Development, Oxford, OUP, 1984. 
dio_- de entre otros, las instituciones financieras internacionales, busca por una parte, conocer el objeto, la estructura orgánica, las competencias y las principales actividades de cada organización, y, por otra, considerar la medida en que la institución toma en cuenta los valores, los principios y las normas radicadas en las perspectivas axiológica, humanística y de desarrollo sustentable del DIE.

\section{Contexto institucional}

El Grupo del Banco Mundial —al que nos referimos en general como el Banco Mundial o BM - está compuesto por el Banco Internacional para la Reconstrucción y el Fomento (BIRF); la Asociación Internacional de Fomento (AIF); la Corporación Financiera Internacional (CFI); el Organismo Multilateral de Garantía de Inversiones (OMGI) y el Centro Internacional de Arreglo de Diferencias Relativas a Inversiones (CIADI). ${ }^{10}$

Como anotábamos al reseñar, el Sistema del Bretton Woods, la creación de la AIF y la CFI responden al interés estadounidense de mantener, bajo el control de un grupo de países afines a su sistema económico, los mecanismos duros de la cooperación para el desarrollo económico. Los otros dos organismos subsidiarios del Grupo responden a necesidades técnicas en sus respectivas materias.

Esto es, a lo largo de dos décadas — los cuarenta y los cincuenta-Estados Unidos buscó a toda costa evitar que los recursos sustanciales para el desarrollo económico se asociaran a institución como la ONU, donde su voto no era susceptible de ser ponderado, y por lo tanto su influencia naturalmente disminuía. Así, bajo la iniciativa estadounidense, el BIRF se convirtió en la entidad financiera principal del Grupo, mientras que la AIF y la CFI adquirieron rasgos accesorios.

De acuerdo con este diseño institucional, el régimen de condicionalidad y las políticas crediticias modelo para el Grupo son en realidad

10 El año de constitución y número de Estados Miembros de cada institución es el siguiente: (i) BIRF, 1945 y 184 miembros; (ii) AIF, 1960 y 164 miembros; (iii) CFI, 1956 y 176 miembros; (iv) OMGI, 1988 y 164 miembros, (v) CIADI, 1966 y 139 miembros. Véase actualizaciones (visita en junio de 2011) en www.worldbank.org. 
decididas por el BIRD. El BIRF oferta así crédito y asistencia para el desarrollo a países de ingresos medios, obteniendo la mayoría de sus fondos mediante la colocación de bonos en los mercados de capital internacionales. El BIRF es el principal organismo de financiamiento del Grupo; obtiene la mayoría de sus recursos en los mercados financieros internacionales mediante la venta de bonos del BM con clasificación AAA a instituciones financieras, fondos de pensiones, bancos centrales, etcétera.

A partir de las estrategias de acción decididas por el BIRF, la AIF instrumenta los créditos para los países menos desarrollados a partir de mecanismos de baja incidencia en la balanza de pagos, incluyendo préstamos sin intereses que provienen de fondos de países en mejor posición económica, y la CFI canaliza capital a empresas privadas y ofrece apoyo técnico y asesoría tanto a empresas como gobiernos. Al estudiar los avances del G20 en la remodelación del sistema veremos cómo el Grupo ha buscado implementar líneas de crédito preventivas y más flexibles, que coadyuven ante crisis como la de 2008-2009.

Por su parte, el OMGI tiene el propósito de incentivar la inversión extranjera en los países en desarrollo mediante la entrega de garantías a inversionistas extranjeros contra pérdidas originadas por riesgos no comerciales. El CIADI, por último, ofrece los medios para solucionar conflictos relativos a inversiones entre inversionistas extranjeros y los países donde han invertido. Ya en el cuerpo de esta sección tendremos ocasión de comentar más de cerca el contexto institucional interno del Grupo.

En una dimensión externa, pero siempre ceñida al ámbito financiero del DIE, es también útil aclarar —al menos con ánimo preliminarla relación entre el BM y el FMI. En este sentido, el FMI y el BM, de acuerdo al diseño de Bretton Woods, se complementan. Mientras que el FMI se centra básicamente en la política macroeconómica y el sector financiero, el BM se interesa principalmente en los temas relacionados con el desarrollo a largo plazo y la reducción de la pobreza. Es por ello que aspectos clave de cada institución —el régimen de condicionalidad y el panel de inspección — son objeto específico de este estudio.

Así, como hemos visto, su actividad incluye el financiamiento concedido a los países en desarrollo y en transición para proyectos de infraes- 
tructura, la reforma de determinados sectores de la economía y las reformas amplias de índole estructural. En cambio, el FMI no financia un sector determinado ni proyectos; sino que respalda la balanza de pagos y las reservas internacionales de un país mientras éste toma las medidas de política necesarias para corregir las dificultades.

También, en la dimensión externa, es necesario considerar la relación de las dos instituciones financieras internacionales con la OMC. Los antecedentes del vínculo entre ambos organismos pueden rastrearse desde la década de los cincuenta a través del GATT. Aunque existen varias categorías de interacción, el objetivo general consiste en evitar contradicciones de competencia entre ambas organizaciones, a partir de los derechos y obligaciones adquiridos por los Estados Miembros adscritos a ambas. Así pues, la practicidad en la razón de ser de este vínculo es no generar cargas dobles o cruzadas que incidan en las condiciones crediticias y de política económica para los países. ${ }^{11}$

Si bien los cimientos de la cooperación se encuentran en los estatutos originales de ambos grupos de entidades, la operatividad de los lazos y la logística de las acciones para la cooperación han quedado detallada, principalmente, en el Acuerdo de Cooperación suscrito entre el FMI y la OMC en 1996. Entre otros aspectos, en él se clasifica la documentación a compartir, la asistencia recíproca a sus respectivas reuniones, la posibilidad de realizar análisis conjuntos, y, en general, una serie de medidas logísticas que tienden a hacer más productiva la relación. ${ }^{12}$

11 Diversos casos resueltos mediante el mecanismo de resolución de controversias de la OMC han advertido la necesidad de que el panel consulte al FMI aspectos clave de la condicionalidad del país objeto de la controversia comercial (derivada de algún tipo de restricción al comercio internacional), que a su vez es acreditado del FMI de acuerdo a ciertos criterios crediticios. Véasen en este sentidon Siegel, D., "Legal Aspects of the IMC/WTO Relationship: the Fund's Articles of Agreement and the WTO Agreements”, AJIL, vol. 92, 2002, pp. 561 y ss.

12 Por existir con antelación a la OMC los estatutos del FMI y el Banco Mundial solamente contienen referencias generales a la cooperación entre organismos. La OMC, sin embargo, contiene referencias explícitas tanto en su carta constitutiva como en declaraciones ministeriales. Así, por ejemplo, el artículo III. 5 de la primera señala: "con miras a alcanzar una mayor coherencia en la elaboración global de políticas económicas, la OMC deberá cooperar como sea apropiado con el FMI y el BIRF y sus organismos afiliados". 
El Convenio Constitutivo del BM establece los propósitos para los cuales fue creado — mismos que deben ser entendidos en el contexto histórico del Bretton Woods que antes hemos comentado- y, desde luego, en la dinámica de la posguerra y la necesidad de Estados Unidos de asegurar su posición geopolítica en Europa. Entre los objetivos que el BM se propone podemos destacar los siguientes: ${ }^{13}$

- Asistir en la reconstrucción y el desarrollo de los territorios de los Estados Miembros, facilitando las inversiones de capitales para propósitos productivos.

- Promover las inversiones privadas de capitales extranjeros mediante garantías o participaciones en los préstamos y otras inversiones efectuadas por inversionistas extranjeros.

- Promover el crecimiento equilibrado a largo plazo del comercio internacional y el mantenimiento del equilibrio de las balanzas de pagos; contribuyendo de igual forma a la promoción de inversiones internacionales para el desarrollo, con atención al aumento de productividad, el nivel de vida y las condiciones de trabajo.

- Ajustar los préstamos concedidos o garantizados con otros préstamos internacionales de origen diverso, dando prioridad a los proyectos más útiles y urgentes, o a los de mayor importancia.

Al estudiar el quehacer del Panel de Inspección del BM, así como la variedad de críticas y las tendencias de reforma, tendremos oportunidad de colegir si los objetivos — sobre todo el tercero- ha sido efectivamente alcanzado o no. Los fines del FMI, como hemos ya dicho, se orientan a buscar un equilibrio en las balanzas de pago de los Estados Miembros, cooperando ante sus dificultades a partir del cumplimiento de ciertos términos de política económica y crediticia, conocido como el régimen de condicionalidad del FMI. Entre los muchos fines del FMI, podemos citar los más relevantes: $:^{14}$

13 Convenio Constitutivo BIRF, artículo I.

14 Estatuto del FMI, artículo I. 
- Fomentar la cooperación monetaria internacional a través de una entidad permanente que opere como mecanismo de consulta y colaboración para resolver los problemas monetarios internacionales.

- Facilitar la expansión y el crecimiento equilibrado del comercio internacional, contribuyendo así a alcanzar y mantener altos niveles de empleo e ingresos reales y de un desarrollo de los recursos productivos, como objetivo básico de política económica.

- Fomentar la estabilidad de los tipos de cambio, procurar que los Estados miembros mantengan regímenes de cambios ordenados y evitar depreciaciones cambiarias competitivas.

- Coadyuvar al establecimiento de un sistema multilateral de pagos para las transacciones corrientes entre los Estados miembros, y con la eliminación de las restricciones de cambios que dificulten la expansión del comercio mundial.

- Infundir confianza entre los Estados miembros, poniendo a su disposición, mediante las garantías adecuadas, los recursos de la institución; procurando así corregir los desequilibrios de sus balanzas de pagos, sin recurrir a medidas perniciosas para la prosperidad nacional o internacional.

- Conforme a los objetivos anteriores, disminuir la duración y aminorar el grado de desequilibrio de las balanzas de pagos de los Estados miembros.

\section{Estructura organizativa}

Ya antes hemos hecho alusión a las entidades del Grupo del BM. Pues bien, cada una de ellas cuenta con un esquema de organización propio, que busca hacer más eficiente el trabajo de todo el grupo. Salvo lo que pueda modificar el G20, como principal organización, el BIRF cuenta con una serie de órganos propios y divisiones, de los cuales consideramos destacables las siguientes: ${ }^{15}$

15 Convenio Constitutivo BIRF, artículos II y IX. Además de los órganos señalados, la estructura básica del BM se complementa con el Consejo Asesor, las comisiones de operaciones de préstamos, las oficinas y los consejos regionales. 
- Junta de Gobernadores. Este consejo es el órgano deliberante supremo, con lo cual las decisiones estratégicas son adoptadas por él. Cada Estado Miembro tiene derecho a designar a un representante. Como ya hemos dicho, a diferencia del resto de las organizaciones de la ONU, el sistema de votación es ponderado de acuerdo a las acciones de las que cada país es titular.

- Administradores. Los administradores del BM son quienes en realidad mantienen el control de la organización, toda vez que cuentan con prácticamente todas las facultades relevantes delegadas de la Junta de Gobernadores. De los veinticuatro administradores, cinco son designados por los Estados Miembros titulares de un mayor número de acciones —Estados Unidos, Japón, Alemania, Reino Unido y Francia - y el resto, por los gobernadores de los demás países.

- Presidente. Esta figura es la responsable de la gestión administrativa del BM, y cuenta, además, con voto de calidad en las reuniones de los administradores. Por ello, es una pieza fundamental en las decisiones del BM pues tiene una especial incidencia en las decisiones de la Junta de Gobernadores.

- Tribunal Administrativo. En una organización de cientos de funcionarios internacionales tanto en Washington como en otras muchas capitales del mundo, hace indispensable contar con un órgano jurisdiccional en materia de trabajo. Esta función es asumida por el Tribunal Administrativo, cuyas decisiones son definitivas. El tribunal está compuesto por siete magistrados elegidos por los administradores, de entre una lista propuesta por el presidente.

Por su parte, y como espejo de la estructura organizativa del BM derivada del nacimiento y fines compartidos bajo el Sistema del Bretton Woods, el FMI cuenta con tres órganos básicos de decisión y administración estratégica, además de una serie de divisiones internas encargadas de la operación cotidiana de la institución: ${ }^{16}$

- Junta de Gobernadores. En similares condiciones de control que el BM, éste es el órgano decisorio supremo del FMI y, en tal sentido,

16 Estatuto del FMI, artículo XII. 
cuenta con todas sus facultades; algunas de las cuales pueden ser delegadas en el directorio ejecutivo. Entre las facultades no delegables se encuentran la de admisión o suspensión de miembros, la aprobación y revisión de cuentas, la modificación uniforme de la paridad de las monedas de los Estados Miembros, la distribución de los ingresos netos y la disolución del FMI.

- Directorio Ejecutivo. La gestión de las operaciones del FMI se lleva a cabo por este órgano. Al igual que en el BM, cinco son designados por el grupo de los cinco países de mayor participación en cuotas, y quince más por el resto de los Estados Miembros.

- Director Gerente. También con las mismas características del BM respecto al presidente, el director gerente, seleccionado por el Directorio Ejecutivo, cuenta con voto de calidad en dicho órgano y es el responsable de la administración del FMI. Desde luego, cuenta con un estrecho vínculo diplomático con los Estados Miembros respecto a los cauces estratégicos a seguir por la institución.

\section{Funciones contemporáneas del BM}

\section{A. Ideas generales}

Como ya hemos señalado preliminarmente, durante los últimos veinte años, la críticas relativas a exigir un mayor respeto de las actividades crediticias del BM y el FMI hacia los derechos humanos y al ambiente han tenido como consecuencia lo que, al menos en el discurso de los organismos, pareciera generar hoy en día un nuevo enfoque a los problemas macroeconómicos. Las lecciones aprendidas de la crisis financiera 2008-2009 han catalizado estos nuevos enfoques que deberán concretarse por el G20. ${ }^{17}$

17 Véanse los ejes del debate generado en torno al rol contemporáneo del BM en Ravallion, Martin, Lessons from Bank Research on Financial Crises, Policy Research Working Paper Series, 2008; Kinley, David, Human Rights and the World Bank: Practice, Politics and Law, Legal Studies Research Paper 07/11, The University of Sydney, 2007; Woods, Ngaire, Unelected Government: Making the IMF and the WB more Accountable, The Brookings Institution, vol. 21, núm. 2, 2003; Woods, Ngaire, The Challenge of Good Governance for the IMF and theWorld Bank Themselves, 
Utilizando la literatura del propio BM, a continuación expondremos algunas de sus principales funciones contemporáneas; en algunas de ellas parece entreverse un creciente - aunque insuficiente - enfoque hacia la dimensión humana de la economía, como resultado de las críticas en que más adelante profundizaremos.

Más allá de las críticas, nadie puede poner en duda que la labor del BM en más de cien países es compleja, y desde luego — aunque insuficiente - muy loable. ${ }^{18}$ A raíz de las críticas que durante las últimas dos décadas se han formulado a su operación crediticia, y gracias al trabajo del Panel de Inspección como cauce de dicho ejercicio, el BM propugna hoy por un efectivo cambio de mirada, y empieza a tomar en cuenta temas no considerados en el pasado de la política sobre desarrollo; entre ellos: género, desarrollo comunitario y pueblos indígenas.

El respaldo a servicios sociales como salud, nutrición, educación y pensiones, prácticamente se ha multiplicado por cinco veces, llegando hoy a más de un $25 \%$ de sus recursos. La forma de trabajo también parece estar cambiando, ya que el BM pretende ser más receptivo a los planes de combate a la pobreza y la inequidad, de acuerdo a lo que los propios países evalúan y aspiran de sí mismos.

En buena medida, mantener el rumbo y fondear al BM con los montos que se requieren dependerá de la congruencia del G20 entre sus declaraciones axiológicas y sus acciones efectivas. Además, alinear la tarea del financiamiento para el desarrollo del G20 con la revisión de los Objetivos de Desarrollo del Milenio (ODM) debe ser el rector de los objetivos.

Según el Informe 2010 del BM, los avances logrados con miras a la consecución de los ODM antes de finalizado el 2015 son evidentes, especialmente en lo que respecta a la pobreza, que se ha reducido en todas las regiones. Sin embargo, a menos de cinco años del vencimiento

World Development, vol. 28, núm. 5, 2000; Banerjee, Abhijit, Rumin, He, TheWorld Bank of the Future, MIT Department of Economics Working Paper núm. 03-06, 2003.

18 Según el Informe Anual 2010 del BM, el financiamiento para el ejercicio 2010 es de US\$44B para 164 operaciones nuevas en 46 países. Los temas financiados son: gestión económica, ambiente, sector financiero y privado, desarrollo humano, sector público, imperio de ley, desarrollo rural, desarrollo social género e inclusión protección social y gestión de riesgos, comercio e integración, y desarrollo urbano. V. BM, Doc 56795, Reseña Anual 2010. 
de los ODM, la consecución de todos los objetivos en todas las regiones será inalcanzable.

El avance con miras a la consecución de los ODM requiere un compromiso especial de los donantes, especialmente en África. La ayuda prestada a este continente ha experimentado un aumento de 5\% anual desde 2000, aunque gran parte de ella ha consistido en alivio de la deuda o asistencia de emergencia y humanitaria, en lugar de financiamiento nuevo. Así, pues, el reto estructural es todavía monumental. ${ }^{19}$

\section{B. Financiamiento para la educación}

Desde luego, el financiamiento para la educación ha sido uno de los puntos centrales de la agenda del BM, con niveles cercanos al 25\% de su cartera total. A raíz de la crisis financiera 2008-2009 y las necesidades propias de los países en desarrollo, el BM está formulando una nueva estrategia de educación que orientará su labor durante la próxima década, enfocado fundamentalmente a logros escolares. Es interesante caer en cuenta del importante aumento que, aunque insuficiente, ha permitido en el 2010 llegar a un monto sin precedente de cerca de US\$5B para educación.

Como lo señala el Informe 2010 del BM, una necesidad clave de atención en todos los proyectos nuevos para educación es la mejora de calidad de la educación. Así, casi la mitad de la totalidad de proyectos nuevos respaldan la enseñanza primaria y abarcan intervenciones como capacitación de docentes, administración escolar descentralizada, participación de la comunidad en las escuelas y atención a las poblaciones marginadas. Aproximadamente una cuarta parte de los nuevos proyectos se centra en la enseñanza secundaria y la formación profesional, con intervenciones para ayudar a asegurar que la educación permita el desarrollo de aptitudes necesarias para satisfacer la demanda del mercado laboral. ${ }^{20}$

19 Como lo explica el Informe 2010 del BM, alcanzar la meta fijada para 2010 habría exigido un aumento de US\$20B en 2009 y 2010, de los cuales se programaron tan solo alrededor de US\$2B. Así, solamente en África el déficit de asistencia es, por lo tanto, de más de US\$18B.

20 Son también interesantes algunos de los proyectos en educación aprobados en el periodo. Así, en marzo de 2010, el Directorio Ejecutivo aprobó dos nuevos proyectos para edu- 


\section{Financiamiento para la lucha contra elVIH/SIDA}

De modo decisivo, la lucha contra el VIH/SIDA ha estado desde la aparición de la pandemia en la prioridad más alta del BM. En este contexto, el BM desembolsó en 2010 un monto de más de US\$300M en apoyo de todas las actividades vinculadas con la lucha contra el VIH para operaciones existentes con un componente de programas de prevención, tratamiento y mitigación.

Como lo expresa el Informe 2010, la mejora de las estrategias nacionales en materia de VIH/SIDA fue un objetivo clave para el BM en este ejercicio. A través de los servicios prestados en el marco de la Estrategia y Plan de Acción contra el SIDA, el BM ayudó a 65 países a mejorar sus respuestas nacionales de lucha contra la pandemia, al aumentar su entendimiento acerca de los riesgos epidémicos y conexos, y formular, así, estrategias nacionales fundadas en datos concluyentes y planes de acción en los que se incluye el cálculo de su costo. ${ }^{21}$

\section{Financiamiento para salud, nutrición y población}

Las inversiones nuevas en programas de salud, nutrición y población alcanzaron un nivel sin precedente de US\$4B en el ejercicio 2010. Las inversiones contribuyen a fortalecer los sistemas de salud, promover la prevención y el tratamiento de enfermedades transmisibles, así como mejorar la higiene, la sanidad y la salud materno-infantil. ${ }^{22}$

Es destacable que en mayo de 2010 el Directorio Ejecutivo aprobó el Plan de Acción de Salud Reproductiva, que pone en funcionamiento el com-

cación correspondientes a India, en virtud de los cuales se proporcionan US\$1B en créditos para aumentar la matrícula primaria. De hecho, uno de los proyectos, que respalda la mejora de los logros escolares y el aumento a la enseñanza primaria es la operación para grande para un país que se haya llevado a cabo desde que el BM empezara a otorgar financiamiento para el sector de la educación en 1962.

21 A fin de fortalecer los sistemas de seguimiento y evaluación de VIH, el BM prestó apoyo técnico a los gobiernos de más de 25 países de África, América Latina y el Caribe, así como Asia central.

22 Entre los resultados más interesantes generados en 2010 se encuentra la elaboración consensuada entre distintos organismos de la reseña de política titulada Scaling Up Nutrition: a Framework for Action, que movilizó el consenso y apoyo para el aumento de las inversiones en intervenciones en materia de nutrición en diversos sectores. 
ponente de salud reproductiva de la estrategia de salud, nutrición y población de 2007. El plan ayuda a los países disminuir la fecundidad, mejorar los resultados de los embarazos y reducir el número de infecciones de transmisión sexual.

\section{E. Colaboración institucional}

También, a partir de 1998, el BM se ha unido a una amplia gama de instituciones colaboradoras en la lucha contra la pobreza alrededor del mundo. Entre ellas, con el Fondo Mundial para la Naturaleza (WWF) para proteger los bosques, y con los sectores público y privado para poner en marcha el Fondo para la Reducción de las Emisiones de Carbono, con el fin de ayudar a mitigar los efectos del calentamiento de la atmósfera.

El BM trabaja con la FAO y el PNUD para patrocinar al Grupo Consultivo sobre Investigaciones Agrícolas Internacionales (CGIAR), el cual hace investigación y capacitación de vanguardia para reducir el hambre y la pobreza, mejorar la salud y la nutrición humanas, así como para proteger el ambiente. Además, a través del Grupo Consultivo de Ayuda a la Población más Pobre (CGAP), el BM e instituciones financieras multilaterales y otros donantes trabajan para mejorar la capacidad de instituciones de microfinanciamiento para prestar servicios financieros a las personas más pobres. ${ }^{23}$

\section{F. Otras funciones}

Si bien las acciones en los rubros anteriores son probablemente las de mayor notoriedad por su impacto en millones de personas y el compromiso de decenas de miles de millones de dólares en financiamiento, existen otros aspectos de la cooperación del BM dignas de mencionar. Aunque desde luego, también incluyen aspectos financieros en las áreas comentadas, se centran en labores de fiscalización, comunicación con la

23 Entre los ejemplos de este rubro destaca el esfuerzo por abrir más de 25 millones de hectáreas al cultivo; además ayuda a combatir enfermedades relacionadas con el ambiente, como la oncocercosis. 
sociedad civil, apoyo a países asolados por guerras y la asistencia para elevar los niveles de participación ciudadana.

Así, por ejemplo, el BM trabaja con más de cuarenta países afectados por conflictos, donde respalda los esfuerzos internacionales por ayudar a las poblaciones asoladas por una guerra a reanudar el proceso de desarrollo en condiciones de paz, así como a prevenir una recaída en la violencia. La labor del BM responde a una serie de necesidades, como dar impulso a la economía, invertir en las regiones afectadas por la guerra, reparar la infraestructura dañadas por el conflicto y poner en marcha programas orientados a grupos vulnerables como viudas y menores. Asimismo, el BM presta su apoyo al desarme, la desmovilización y la reintegración de excombatientes, así como a iniciativas sobre detección de minas terrestres. ${ }^{24}$

Ya hemos dicho que la actividad del BM en aspectos de desarrollo ha tenido importantes claroscuros. Sin embargo, los últimos quince años se ha caracterizado por una presencia mucho más sólida en que, tanto el Panel de Inspección, como la crítica académica y de la sociedad civil mediante ONG's ha permitido en lo posible, regresar a la tendencia por encarrilar los trabajos del FMI y el BM a una dimensión más humana del desarrollo. Desde luego, habrá que poner algunos años de distancia para saber si el discurso del cambio de enfoque del BM ha sido efectivo.

6. Críticas a las funciones estructurales del FMI y el BM:

especial referencia a la perspectiva jurídico-humanista

\section{A. Ideas generales}

Parece recomendable formular primero un breve recuento de las críticas que la doctrina ha intentado ya sistematizar, mediante el estudio de

24 Entre los proyectos de amplio alcance sustentados por el BM se incluyen los esfuerzos de reconstrucción de la infraestructura y el empoderamiento de las comunidades en Afganistán, la rehabilitación de niños de la calle en la República Democrática del Congo, las actividades para impulsar el desarrollo local en el Sur de Serbia, la capacitación de nuevos empleados públicos en Timor Oriental y los programas nacionales de formación de consenso y de participación ciudadana en Haití, por citar algunos. 
posicionamientos de ONG's, medios de comunicación y académicos en la materia. La idea es que este epígrafe preliminar nos sirva como una primera aproximación de conjunto a la crítica en materia de derechos humanos.

Una vez hecho ese primer vistazo a la sistematización de la crítica en la doctrina, trataremos de poner en relieve las categorías de fuentes normativas en materia de derechos humanos; así como los contenidos y las modalidades de las obligaciones impuestas en instrumentos internacionales; para después concretar, mediante un breve repertorio individualizado, las obligaciones básicas de derechos humanos, que los sujetos de Derecho Internacional Público (DIP) deben tomar en cuenta al negociar instrumentos financieros.

Como tercer paso, si bien por el objetivo y la extensión de este trabajo, no se ahonda en el régimen de condicionalidad del FMI a la luz del derecho internacional de los derechos humanos, vale señalar que lo que aquí se expone respecto al BM es, mutatis mutandi, aplicable al FMI. Una remodelación del sistema financiero internacional que desconozca las obligaciones de los Estados miembro, en otras disciplinas (como en derechos humanos y ambiente) sería, no solamente restrictiva, sino, lisa y llanamente, errónea.

B. Consideraciones específicas sobre derechos humanos

Para iniciar es necesario recordar que las fuentes de obligaciones de derechos humanos tanto para los Estados como para las instituciones financieras internacionales son los tratados en la materia, la costumbre internacional y los principios generales del DIP.

En principio parecería que ni el FMI ni el BM tendrían porqué preocuparse del derecho internacional de los derechos humanos por no estar vinculados a sus instrumentos, y, más aún, por tener prohibiciones a considerar cuestiones distintas a las económicas - como el caso del FMI —. Sin embargo, como acertadamente expone S. Skogly, lo anterior no implica que esta disciplina no sea de importancia para su función. ${ }^{25}$

25 Véase Skogly, S., “The Human Rights Obligations of the World Bank and the IMF”, en Genungten, W. et al., WB, IMF and Human Rights,WLP, Nijmegen, Países Bajos, 2003, pp. 50 y ss. 
En efecto, la codificación de normas de derechos humanos tiene una contribución significativa para comprender cabalmente el concepto de estándares de derechos humanos, a los que suelen hacer referencia los instrumentos de servicios financieros de las instituciones. Así, podemos colegir que estos estándares, derivados de las normas de los tratados en la materia, trascienden a la esfera de la costumbre internacional, a pesar de que ni el BM ni el FMI sean actores directos en la materia.

Aunque el rol de promotores - o al menos, no opositores - de los derechos humanos de reconocimiento universal, por parte del FMI y el $\mathrm{BM}$, es todavía objeto de discusión en la doctrina, desde mediados de la década de los noventa puede observarse una dinámica hacia este sector, a partir de nuevos enfoques de ambos organismos. Bajo nuestro criterio, esta tendencia no responde sólo a la presión de la sociedad civil, sino al reconocimiento de diversos contenidos del derecho internacional de los derechos humanos como costumbre internacional. ${ }^{26}$ La crisis financiera 2008-2009 ha potenciado énfasis de la sociedad civil.

Más aún, es necesario tener en cuenta que los acuerdos de la ONU con el FMI y el BM, respectivamente, son también una señal de entendimiento generalizado sobre los derechos humanos por parte de las instituciones financieras, máxime que el Consejo Económico y Social de las Naciones Unidas (ECOSOC) tiene incluso facultades supervisoras sobre sus actividades.

De acuerdo con todo lo anterior, si bien es cierto que no necesariamente todos los derechos, ni todos los aspectos de cada derecho justifican ser considerados costumbre internacional, sí, al menos, algunos esenciales como los destacados en la Declaración Universal de los Derechos Humanos y a la interpretación de éstos por órganos competentes.

En nuestra opinión, una buena ilustración de este criterio puede ser el derecho establecido en el artículo 25 de dicha Declaración, en la cual se

26 V. Darrow, M., Between the Light and the Shadow:WB, IMF and Human Rights, Portland, Hart, 2003, pp. 53 y ss.; Shlemmer, S., "The Impact of Civil Society on the World Bank, the International Monetary Fund and the World Trade Organization: the Case of the World Bank", ILSA Journal of Interational \& Comparative Law, vol. 7, 2001, pp. 402 y ss.; Clark, D., "The World Bank and Human Right. The Need of Greater Accountability", Harvard Human Rights Journal, vol. 15, 2002, pp. 205 y ss.; Horta, K., Rhetoric and Reality: Human Rights and the World Bank, Harvard Human Rights Journal, vol. 15, 2002, pp. 227 y ss. 
especifica, entre otras cosas, que toda persona tiene derecho a un nivel de vida adecuado que le asegure, así como a su familia, la salud y el bienestar, y en especial la alimentación, el vestido, la vivienda, la asistencia médica y los servicios sociales necesarios.

La norma es claramente una obligación directa de un tratado internacional para el Estado Miembro al momento de negociar su carta de intención ante el FMI, y una obligación de costumbre internacional para el FMI, al imponer un régimen de condicionalidad que notoriamente vaya en contra del presupuesto social destinado a hacer efectivo este derecho humano. ${ }^{27}$

Así, aunque se tengan todavía algunas dudas respecto al tratamiento detallado del FMI o el BM en la materia, es claro que los Estados son susceptibles de incurrir en responsabilidad internacional por desconocer en sus negociaciones crediticias las normas sobre derechos humanos. De tal forma, se encuentran igualmente sujetos a la inspección y judicialización necesarias, mediante órganos internacionales, tales como la Comisión de Derechos Humanos de la ONU o la Corte Interamericana de Derechos Humanos, a través de los procedimientos existentes para uno y otro supuesto.

Ahora bien, los contenidos de los derechos humanos para el propósito de analizar su relación con los créditos del FMI y el BM suelen considerarse como de respeto, de protección o de promoción. En este orden, el deber de respeto impone simplemente no interferir con ellos; de abstenerse de realizar cualquier acción que viole la integridad o libertad del individuo.

De acuerdo con este segundo peldaño, el deber de protección implica la necesidad de regular las actividades de terceros, con el fin de que mediante ella no violen la integridad de terceros. Finalmente, el deber de promoción se basa en la insuficiencia de las dos medidas anteriores, con lo cual, el Estado debe tomar todas las medidas necesarias para garantizar la integridad y la libertad de la persona.

27 El derecho a percibir alimentos ha sido además sujeto a una interpretación sistemática por parte de la Comisión de Derechos Humanos de la ONU desde 1987. V. UN Doc. E/ CN.4/Sub.2/1987/23. Véase también Horta, K., Rhetoric and Reality: Human Rights and the WB, Harvard HRJ, V. 15, 2002, y Clarke, D., "The WB and Human Rights", Harvard HRJ, vol. 15, 2002. 
Las obligaciones para el Estado Miembro en cada uno de los tres estadios parecen claramente identificables. ¿Cuál es, sin embargo, el rol de las instituciones financieras respecto a cada nivel? El respeto sólo puede manifestarse en que la condicionalidad y el seguimiento de las políticas económicas impuestas por el FMI no vulneren la integridad de las personas, ni atenten contra su libertad para utilizar los recursos materiales para satisfacer sus necesidades; todo ello en la sociedad del Estado Miembro acreditado. Por lo que respecta al BM, el deber de respeto se centra en que los créditos otorgados no tengan un efecto nocivo para individuos que viven en la región donde se aplicarán estos, o bien para el ambiente del lugar en cuestión. Como después veremos, el Panel de Inspección del BM ha sido el encargado de vigilar el cumplimiento de esta tarea.

En este orden de ideas, el deber de protección de una institución como el FMI implica controlar a los terceros que actúen por su cuenta, bajo cualquier tipo de relación jerárquica o contractual. La promoción, como categoría más alta, deviene de las dimensiones de los derechos humanos que hayan de ser consideradas por las instituciones financieras como verdadera costumbre internacional.

Desde luego, no es propósito de este trabajo ofrecer un listado exhaustivo de los instrumentos internacionales de derechos humanos, en donde se señalen, una a una, las normas sustantivas o adjetivas, y los rasgos de éstas, que obligan a los Estados — en virtud de los tratados en sí- y a las instituciones financieras internacionales — con jerarquía de costumbre internacional_- Sin embargo, parece prudente destacar sólo algunas de las facultades y obligaciones universales más relevantes: ${ }^{28}$

- Declaración Universal de los Derechos Humanos (1948). Derecho a un nivel de vida adecuado, incluido en ello la salud y el bienestar; la alimentación, el vestido, la vivienda, la asistencia médica y los servicios sociales necesarios. Seguro en caso de desempleo, enfer-

28 Ghandhi, P., Blackstone's Statutes, International Human Rights Documents, OUP, 2004; Pinto, M., The Legal Context: Concepts, Principles, Standards and Institutions, en International Economic Law with a Human Face, cit., pp. 13 y ss.; Sfeir, A., "Human Rights and Economic Development: Can They be Reconciled: a View from the World Bank", en World Bank, IMF and Human Rights, cit., p. 3. 
medad, invalidez, viudez, vejez, u otros casos de pérdida de sus medios de subsistencia por circunstancias independientes a la voluntad (artículo 25).

- Carta de las Naciones Unidas (1945). Facultad de la Asamblea General y del ECOSOC respectivamente para hacer recomendaciones para fomentar la cooperación internacional en materias de carácter económico, social, cultural, educativo y sanitario, y ayudar a hacer efectivos los derechos humanos y las libertades fundamentales, sin hacer distinción por motivos de raza, sexo, idioma o religión (artículos 13 y 62).

- Pacto Internacional de Derechos Civiles y Políticos (1967). Derecho a la libre determinación de los pueblos, y, en virtud de él, derecho a establecer libremente su desarrollo económico y social. Prohibición de privar a un pueblo de sus propios medios de subsistencia (artículo 1o.).

- Pacto Internacional de Derechos Económicos, Sociales y Culturales (1976). Derecho a gozar de condiciones de trabajo equitativas y satisfactorias (artículo 7o.).

- Convención Internacional sobre la Eliminación de Todas las Formas de Discriminación Racial (1966). Prohibición y eliminación de la discriminación racial en todos los derechos económicos, sociales y culturales (artículo 5o.).

- Convención sobre la Eliminación de Todas las Formas de Discriminación contra la Mujer (1979). Derecho a las mismas oportunidades de empleo e igual remuneración, prestaciones, seguridad social y salud (artículo 11).

- Convención sobre los Derechos del Niño (1989). Derecho a estar protegido contra la explotación económica y contra el desempeño de cualquier trabajo que pueda ser peligroso o entorpecer su educación, o que sea nocivo para su salud, o para su desarrollo físico, mental, espiritual, moral o social (artículo 32).

- Declaración de la Asamblea General de la ONU sobre el Derecho al Desarrollo (1986). Derecho y deber de los Estados de formular políticas de desarrollo nacional adecuadas con el fin de mejorar constantemente el bienestar de la población entera y de todos los individuos, sobre la base de su participación activa, libre y significativa 
en el desarrollo y en la equitativa distribución de los beneficios resultantes de éste (artículo 2).

Claro está que a este listado podría sumarse el derecho convencional en materia ambiental; disciplina que en todo caso reviste uno de los niveles de la escala de los derechos humanos: los de tercera generación.

\section{LA CRISIS FINANCIERA INTERNACIONAL DE 2009 Y LOS PRIMEROS BOCETOS DEL G20 EN LA ARQUITECTURA DEL SISTEMA FINANCIERO INTERNACIONAL ${ }^{29}$}

\section{La génesis y los primeros pasos del G20}

Si bien el G20 ha adquirido un papel protagónico ante la crisis financiera global iniciada en 2008 y padecida primordialmente en 2009, lo cierto es que su creación data de 1999. Originalmente, había sido el G7 (Estados Unidos, Reino Unido, Alemania, Francia, Italia, Japón y Canadá) el orquestador de la transición del sistema monetario internacional creado con Bretton Woods de un esquema de paridades fijas a uno de cambios flexibles. ${ }^{30}$

La causa que — con el liderazgo de Canadá y de Alemania — detonó la creación del G20 (G7 más China, India, Indonesia, Corea del Sur, Australia, Brasil, México, Argentina, Arabia Saudita, Turquía y la Unión Europea), ${ }^{31}$ como un foro de discusión más abierto, en el cual, econo-

29 Véanse las declaraciones y documentos acordados del G20 en su propio sitio (visita en junio de 2011) www.g20.org.

30 Véase el contexto de los trabajos del G20 en: Brumer, Chris, How International Financial Law Works (and how it doesn't), Georgetown University Law Center, 2010; Nordberg, Donald, Return of the State? The G20, the Financial Crisis and Power in the World Economy, Londres, The Board Agenda, 2009.

31 La presidencia en el G20 de la Unión Europea rota, con lo cual se tiene una participación directa de los miembros de la UE no representados directamente). Para conocer la posición de la UE ante la crisis financiera mundial véase Subdirección General de Asuntos Económicos y Financieros de la UE; "La respuesta europea a la crisis financiera y económica", Boletín Económico de ICE, núm. 2957, enero de 2009, pp. 19 y ss. 
mías emergentes participarían con voz, fue la crisis financiera asiática. En términos generales, las economías del G20 representan más del 85\% del PIB, más del 80\% del comercio y 2/3 partes de la población mundial. Su representatividad, y por tanto, lo que la sociedad civil espera del G20, está pues, sobradamente acreditada.

En este contexto, crisis monetarias recurrentes, como la de México de 1995, Sudeste asiático de 1997, Rusia de 1998 y Brasil de 1999 confirmaron la inestabilidad monetaria sistémica y el nivel de contagio internacional, dando con ello lugar a la necesidad de contar con un espacio de discusión y coordinación de políticas financieras internacionales: el G20.

La estructura del G20 incluye una presidencia rotativa y la presencia exofficio del director gerente del FMI, el presidente del Banco Mundial y los presidentes del Comité Monetario y Financiero Internacional del FMI, así como del Comité para el Desarrollo del Banco Mundial. Por cada uno de los países miembros comparecen a las sesiones el ministro de Hacienda, el presidente del Banco Central, así como un delegado. Desde luego, como veremos, a raíz de 2008 el G20 ha atraído la presencia de jefes de Estado y de gobierno.

Desde el punto de vista de funcionamiento, el G20 se diseñó como un foro de debate informal, en donde no existen instancias de votación. Así, si bien no goza de una instancia formal preestablecida, lo que ahí queda consensuado suele tener una expresión formal en las políticas públicas del FMI y del BM, entre otras instancias multilaterales y regionales. Existe, desde 2002, un mecanismo de elección y rotación tripartito. La presidencia por país tiene una duración de un año, la cual arterna países de distintas regiones y con distinto nivel de desarrollo económico.

Como señalan Martin Abeles y Esteban Kiper, ${ }^{32}$ existen dos aproximaciones polares para comprender la constitución del G20: la hegemónica y la cooperativa. Quienes se adhieren a la primera asumen que la creación del G20 y la incorporación del mundo emergente a la mesa de negociación responden a la lógica de la dominación del mundo desarro-

32 Abeles, Martin y Kiper, Esteban, El G20 ¿Hacia una nueva arquitectura financiera internacional? El rol de Argentina, México, Brasil, Buenos Aires, Observatorio de Política Exterior Argentina, 2010, pp. 4 y ss. 
llado, que convoca al nuevo foro con el fin de legitimar decisiones que seguirán estando en su poder.

El enfoque cooperativo - siguen los autores — entiende que la creación del G20 involucra un cambio más profundo en la estructura de gobernanza internacional e implica una instancia de mutua influencia y mayor equilibrio en la toma de decisiones. Si bien la política exterior de Alemania y de Canadá — principales impulsores de la creación del G20 permite cierto margen de credibilidad en la real voluntad del mundo desarrollado en incorporar al resto de los miembros, lo cierto es que la legitimidad de los actores emergentes del G20 solamente puede darse a partir de un efectivo re diseño de la arquitectura financiera internacional, y no de una simple adición al conservadurismo hegemónico manifestado por décadas desde Bretton Woods.

Antes de 2008 — hito en la evolución del grupo dada la crisis financiera global — el G20 produjo resultados francamente limitados en el ámbito financiero y de desarrollo. Así, con un nivel de avance francamente modesto, los temas han abarcados (i) el combate al financiamiento para el terrorismo; (ii) el fortalecimiento de las facultades del FMI para supervisar programas de evaluación de la estabilidad financiera de sus miembros; (iii) crecimiento sustentable; (iv) financiamiento para el desarrollo; (v) restructuración de deuda de países emergentes; (vi) prioridades de política económica según el consenso de Washington; (vii) reformas institucionales del FMI y del BM, y (viii) líneas de crédito contingente para evitar contagios financieros.

\section{El inconcluso rol del G20 tras la crisis financiera global de 2009}

\section{A. Las tensiones por definir la agenda del G20}

El estallido de la crisis financiera global de 2008 puso - como nun$\mathrm{ca}$ - al descubierto la fragilidad del sistema monetario internacional, abandonado por el FMI, para prevenir y, en su caso, reaccionar a tiempo a un error sistémico de los niveles de la citada crisis.

Pues bien, fue a partir de la franca imposibilidad de hacer frente a la crisis de modo nacional e incluso regional que a raíz de la iniciativa del presidente Sarkozy de Francia y del primer ministro Brown de Reino 
Unido, en octubre de 2008 el presidente Bush convocó a un primer encuentro que tuvo lugar en Washington en Noviembre de 2008 33 . La incorporación al G20 de los jefes de Estado y de gobierno marcó, sin duda, una nueva etapa en la vida del G20. Ésta, si bien se encuentra lejos de alcanzar sus metas, se ha caracterizado por un dinamismo y liderazgo mucho mayor, que el ejercicio por los ministros de hacienda y gobernadores de bancos centrales; actores tradicionales del G20 hasta entonces.

Desde las primeras sesiones quedaron abiertas las posiciones de los diversos países que integran el crisol de países del G20. Por una parte, el bloque anglosajón ha sido el principal proponente de las políticas macroeconómicas contra-cíclicas, tanto fiscales como monetarias. Sin embargo, ha sido contrario a desarrollar nuevas regulaciones sobre mercados financieros. Por su parte, el bloque europeo, si bien ha demostrado ser menos agresivo en políticas anti cíclicas, ha sido incisivo en cuanto a la necesidad de regular áreas de riesgo hasta ahora prácticamente libres de control, como los fondos de riesgo, los paraísos fiscales, las agencias calificadoras de riesgo crediticio, las remuneraciones de los directivos financieros, etcétera.

La actuación más importante de los BRICs fue la de China, quien por sus características contemporáneas y el nivel de sus activos monetarios ha tenido un peso muy significativo. Así, si bien China ha acompañado tibiamente tanto al bloque europeo como al bloque anglosajón, lo cierto es que no ha colaborado en la política de transparencia financiera. En todo caso, el rol de China como — hoy en día — la segunda economía mundial, su nivel de reservas internacionales y su capacidad industrial, la han convertido como un interlocutor obligado en la arquitectura de cualquier institución internacional, máxime siendo ésta financiera. Desde luego, en el ámbito de su rol como actor renovado del escenario internacional, China no ha escapado de importantes críticas económicas y sociales —además de ambientales, políticas y de múltiples índoles-. Así, por ejemplo, en su Reporte Económico de 2010 sobre China, la OCDE se concentra en siete recomendaciones centrales: (i) mejorar las

33 Hasta la fecha de elaboración de este artículo, las cumbres del G20, a partir de Washington 2008 han sido: Londres (abril de 2009); Pittsburg (septiembre de 2009); Toronto (junio de 2010); Seúl (noviembre de 2010). La próxima sesión está programada en Cannes, en noviembre de 2011. 
bases de su política monetaria; (ii) abrir los mercados financieros; (iii) disminuir sus barreras comerciales; (iv) unificar sus redes de seguridad social; (v) facilitar la movilidad social; (vi) consolidar su régimen de pensiones, y (vii) llevar a cabo una reforma a su sistema de salud. ${ }^{34}$

Pues bien, en comparación con los BRICs —incluida la poderosa China_-, lo cierto es que el resto de los países emergentes —incluido México - han tenido una participación menos significativa en el G20, acompañando la generación de consensos, sin ser líderes de opinión.

Como enseguida desarrollaremos, si bien los países desarrollados -bloque anglosajón y europeo- han fortalecido la capitalización del FMI, del BM y de los bancos de desarrollo regionales, han sido francamente reticentes a instrumentar cambios de cuotas y votos. Desde luego, éste ha sido uno de los puntos de tensión en relación con los BRICs y con el resto de países emergentes que buscan una participación más democrática y representativa en tales instituciones.

Pues bien, los cuatro grandes bloques temáticos del G20 a partir de la crisis financiera iniciada en 2008 son: (i) crecimiento balanceado y sostenido; (ii) reforma al sector financiero; (iii) instituciones financieras internacionales y desarrollo; (iv) lucha contra el proteccionismo y promoción del comercio internacional. De estos cuatro bloques de la agenda nos concentraremos en los tópicos relacionados con la reforma a las instituciones financieras internacionales, para luego particularizar en una asignatura específica de reforma en el BM: el Panel de Inspección. Esto a partir de lo convenido en Seúl 2010 (el Documento de Seúl).

3. Más allá de Cannes 2011: los ejes de la reforma a las instituciones financieras internacionales

Como contexto al capítulo sobre reformas a las instituciones financieras internacionales, el Documento de Seúl señala cómo a partir de acuerdos del propio G20, generados en medio de la crisis de 2009, se movilizaron recursos por más de US750B a través del FMI, así como más de US\$235B a través de bancos multilaterales de desarrollo, incluido el

34 Véase OCDE, Reporte Económico sobre China, Serie Reportes Económicos, París, 2010. 
BM. Esta masiva movilización de recursos críticos favoreció la recuperación de la economía mundial.

Sin soslayar la importancia de los otros puntos de la agenda del G20, especialmente la reforma al sector financiero, por ser el objeto de este trabajo, nos concentraremos ahora en los ejes de las reformas al FMI y al BM y los bancos multilaterales de desarrollo. Como veremos, el proceso de implementación de las reformas está proyectado a distintos plazos.

\section{A. Ejes de las reformas al FMI}

Las reformas propiciadas por el G20 en el FMI han buscado mejorar tanto el sistema de cuotas como la gobernanza. Como se verá, las reformas, de implementarse correctamente, parecen un paso importante hacia una FMI más legítimo, creíble y efectivo; reconociendo con ello las nuevas realidades de la economía global. En este sentido las reformas incluyen:

- Con el fin de ser completado en la cumbre de 2012, se pretende un cambio en las cuotas hacia los mercados emergentes más dinámicos, hacia los países en desarrollo en general, y en particular hacia las naciones subrepresentadas y más pobres del mundo;

- Una duplicación de cuotas con la correlativa incursión de los llamados Nuevos Acuerdos para Créditos (NAB);

- Continuar con el proceso que tiende a aumentar la voz y representación de mercados emergentes y economías en desarrollo, incluidas las naciones más pobres, a través de una revisión integral de la fórmula de cuotas para el año 2013, de modo que los pesos económicos por nación estén mejor balanceados. Se acordó igualmente una nueva revisión integral de cuotas para el 2014;

- Mayor representación de las economías emergentes y los países en desarrollo, en el Consejo de Administración;

- Transitar hacia un Consejo totalmente electo, teniendo en cuenta el compromiso de los Estados miembros, de mantener 24 puestos. A partir de la 14a. Revisión General, una reforma a la composición del Consejo cada ocho años. 
- Aumentar la supervisión del FMI con un énfasis en la detección de riesgos sistémicos y contingencias. En ese sentido, se logró ya implementar por parte del propio FMI el examen de estabilidad financiera a través del Programa de Evaluación del Sector Financiero (FSAP);

- También en el ámbito de la supervisión del FMI, el G20 determinó continuar el diseño e implementación de políticas en evaluación sobre estabilidad financiera, macroeconomía, políticas estructurales y en materia cambiaria, aumentando así la sinergia entre herramientas de evaluación y ayudando a sus miembros a mejorar sus propias capacidades de supervisión.

Nos parece que un siguiente paso en la ruta de trabajo del G20 es analizar si las acciones tomadas, así como los proyectos por implementar, son realmente consecuentes con las recomendaciones de la Comisión de especialistas creada a iniciativa del gobierno francés en la primavera de 2008. De las declaraciones y documentos generados por el G20 en la materia no parece que las recomendaciones tengan todavía el eco necesario.

\section{B. Ejes de reformas al BM y a los bancos multilaterales de desarrollo}

- Con relación a los fondos necesarios para las operaciones de estas instituciones financieras, el compromiso ha sido completar el ambicioso remplazo de las líneas de crédito;

- Fortalecer redes financieras globales que sean efectivas para asistir a los Estados a limitar la volatilidad financiera, incrementar su acumulación de reservas y, con ello, reducir la incertidumbre financiera evitando bandazos en el flujo de capitales;

- Optimizar el sistema de Línea de Crédito Flexible (FCL), incluyendo la extensión de su duración y la remoción de límites. Así, países con sólidos fundamentos y políticas tendrán acceso a este tipo de crédito, mismo que mejorará también en términos de predictibilidad y eficacia al solicitante;

- Implementar la nueva herramienta preventiva conocida como Línea de Crédito Preventiva (PCL), misma que permite a países con 
fundamentos y políticas sólidas, pero con vulnerabilidad moderada, beneficiarse de este tipo de liquidez originada por el FMI;

- Con la colaboración del FMI, desarrollar programas colaborativos para mejorar la prevención de crisis de naturaleza sistémica, teniendo en cuenta las características regionales.

Al igual que en el caso del FMI, los programas de trabajo que ha seguido el G20 respecto al BM y los bancos multilaterales no parecen tener en cuenta las recomendaciones de la Comisión. Esto es, el enfoque económico sigue siendo el clásico. Como el caso del FMI, lo que parece palearse son los efectos de la crisis financiera, pero no las causas de fondo que deben implicar una perspectiva auténticamente social de la economía, sin despreciar con ello las ventajas de las economías de mercado.

\section{El PANEL DE INSPECCiÓN DEL BM - UNA ASIGNATURA PENDIENTE} DEL G20 EN LA REMODELACIÓN DEL SISTEMA FINANCIERO INTERNACIONAL DEL SIGLO XXI

\section{Ideas generales y antecedentes}

Hemos dicho antes que las críticas formuladas desde la década de los ochenta al FMI y al BM no han tenido una respuesta uniforme. En efecto, si bien en algunos casos — como el de la lucha contra la pobreza y el alivio de la deuda - la posición es común, en la mayoría de los supuestos cada institución ha reaccionado de manera e intensidad distinta.

Así por ejemplo, el FMI ha tenido una reacción muy decidida al transparentar sus procesos y decisiones; pero no parece haber tenido todavía la voluntad política para, entre otras muchas exigencias, ser más sensibles a la condicionalidad impuesta a sus acreditados; o para revisar el sistema de votación ponderada.

El BM por su parte, tampoco parece haber dado pasos hacia la democratización entre sus miembros; sin embargo ha sido más asertiva en reconocer sus errores e incorporar más razonablemente consideraciones de derechos humanos, de género, de ambiente, de identidad cultural de 
los pueblos indígenas, etcétera. Desde nuestro punto de vista, este acierto deriva en buena medida de la creación de su Panel de Inspección en 1993. Si bien su creación misma es atinada, su eficacia y legitimidad en la supervisión del BM tiene todavía un largo camino por andar.

Es justo señalar, como bien explica I. Shihata que la creación por el BM de un mecanismo independiente que examinara la medida en que la institución efectivamente alcanzaba los estándares que se ha fijado respecto al diseño, valoración e implementación de sus operaciones fue un trabajo sin precedentes en la historia de los organismos internacionales de carácter universal. ${ }^{35}$

La instauración de un sistema de inspección autónomo fue un proyecto abanderado por el entonces presidente del BM, L. Preston a partir de la opinión de diversas voces - internas y externas - que con razón afirmaban la ineficacia del BM en lograr un nivel adecuado de estándares internacionales en sus políticas y procedimientos. La comisión especial de estudio formada para este efecto concluyó en 1992 la necesidad de mejorar la gestión de su portafolio crediticio, optimizando las funciones del Departamento de Evaluación de Operaciones.

Sin embargo, las conclusiones más importantes de esta comisión consistieron en sugerir una participación más activa tanto del acreditado como de las personas que serían afectadas por el proyecto financiado. Para ello, la acción más efectiva era constituir un Panel de Inspección como mecanismo efectivo de evaluación independiente de la actividad del BM. Estas conclusiones son un hito importante en el reconocimiento de las ONG's como un interlocutor en los procesos de las instituciones internacionales, que más tarde tendría su respectivo eco en otras organizaciones, como la OMC.

La constitución del Panel no fue, sin embargo, sólo objeto de reingeniería organizativa del BM, sino, como en la mayor parte de los casos de la actividad humana, resultado de una cadena importante de desaciertos. Es así necesario dar un paso más hacia atrás. En efecto, el debate por la falta de criterio integral en el otorgamiento de créditos tomó un especial énfasis a partir de dos importantes proyectos de infraestructura

35 Shihata, I., "The World Bank Inspection Panel - Its historical, legal and operational aspects", en Alfredsson, G. y Ring, R., The Inspection Panel of the World Bank: a different complaints procedure, Kluwer, La Haya, Países Bajos, 2001, pp. 8 y ss. 
en la India de mitades de los años ochenta, llevado a cabo parcialmente con recursos del BM. ${ }^{36}$

El proyecto implicaba una gran presa de capacidad de generación eléctrica de 1,200 megawatts y con suficiencia para irrigar más de dos millones de hectáreas en Gujarat, India. Desde sus inicios, el proyecto crediticio no contó con una gestión adecuada para analizar dos grandes inconvenientes: el impacto ambiental que tendría en la zona, y el desplazamiento de más de 120,000 personas. Con ello, era claro que en este caso, y probablemente en muchos más, la atención adecuada a las implicaciones sociales y ambientales de los proyectos a financiar era simplemente ignorada. ${ }^{37}$

El efecto del proyecto en el país y en los medios de comunicación globales llevó a que, el entonces presidente del BM, B. Conable ordenara en 1991 la constitución de una comisión de investigación a cargo de B. Morse, un funcionario retirado de la ONU y congresista en los Estados Unidos. Los errores manifiestos en la aprobación y seguimiento del crédito motivaron a la comisión a sugerir una revisión integral de los procedimientos operativos y de inspección del BM. El proyecto, como hemos dicho, habría de ser abanderado meses más tarde por el siguiente presidente del BM.

Un primer avance formulado por cuatro directores ejecutivos - $-\mathrm{y}$ más tarde apoyado por otros cinco_- en 1993, consistió en establecer una pequeña unidad autónoma encargada de revisar proyectos al azar, y de analizar otros que fueran cuestionados por los países acreditados o bien por directores ejecutivos. Así, no se contemplaba todavía la posibilidad de tramitar quejas de las partes afectadas por el proyecto.

En otras etapas del proyecto se consideraron al menos tres posibilidades más. La primera consistía en delegar tales funciones en una especie de ombudsman interno del BM; la segunda, en crear una comisión externa independiente con facultades jurisdiccionales y capacidad de obligar al BM con sus resoluciones. La tercera proponía un mecanismo en dos etapas: la primera consistía en una reclamación a ser formulada ante un

\footnotetext{
36 Alfredsson, G., "Introduction: Broadening the Scope of Aplicable Standards", pp. 47 y ss., así como Clark, D. y Hunter, D., "The World Bank Inspection Panel -Amplifying Citizen Voices", pp. 167 y ss.; ambos en The Inspection Panel of theWorld Bank, cit.

37 Schlemmer, S., “The Inspection Panel's Case Law”, The Inspection Panel, cit., pp. 87 y ss.,
} 
órgano interno del BM, y sólo ante la insatisfacción del resultado, elevarla ante un órgano externo que vinculara a la institución. Los vaivenes de este proceso culminaron en 1997; se concretó el estatus del Panel de Inspección como un cuerpo con facultades independientes, pero dentro de la estructura de la institución.

\section{Estructura, objetivos y funciones}

De acuerdo con la resolución, el Panel de Inspección se compone por tres miembros de distintas nacionalidades, nominados por el presidente y designados por el Consejo de Directores Ejecutivos. Entre los requisitos para ser nombrados se incluye su habilidad, integridad, independencia de la administración del BM, conocimiento y experiencia ante asuntos de desarrollo y condiciones de vida en países en desarrollo. Para fortalecer la independencia de los miembros del Panel se establece que no pueden haber trabajado en el BM al menos dos años antes, y no pueden volver a él después de haber servido en el Panel.

Los miembros del Panel solamente pueden ser removidos por causa suficiente por decisión del Consejo de Directores Ejecutivos, y el cargo tiene una duración de cinco años. El presidente del Panel debe trabajar de tiempo completo en los asuntos de su competencia; los otros dos trabajan parcialmente, pero pueden hacerlo de modo completo si la carga de trabajo lo amerita. Además, el Panel cuenta con su propio Secretariado para la tramitación de los asuntos. Los gastos totales del Panel son financiados por el presupuesto del BM.

A pesar de que los objetivos no están listados detalladamente en la resolución, pueden ser colegidos del proceso de debate sobre su constitución. En suma, puede entenderse que los propósitos del Panel son elevar el control de calidad en el diseño del proyecto, su valoración e implementación; evitar posibles daños a la población, transparentar sus operaciones y fiscalización, y velar por la observancia de las políticas y los procedimientos del BM, a lo largo de todo el ciclo del financiamiento.

Tanto la Resolución 93-10 del BM, a la que hemos hecho referencia, como los procedimientos son las fuentes normativas que dan vida a la operación del Panel de Inspección. Desde luego, no es nuestra inten- 
ción profundizar en el procedimiento de denuncia ante el Panel, pero conviene tener una referencia general de su mecanismo. El Panel responde a las solicitudes de inspección — denuncias - por al menos dos personas que vivan en un país afectado por el proyecto financiado. ${ }^{38}$

Bajo ciertos criterios de legalidad procesal detallados en su normatividad, el Panel evalúa la solicitud, así como la respuesta del BM y las pruebas pertinentes. A partir de ello, formula una recomendación a los directores ejecutivos sobre la conveniencia de investigar a fondo la solicitud. Así, la decisión para seguir adelante sólo puede ser tomada por dicho Consejo.

Una vez realizada la investigación autorizada, el Panel prepara una resolución resumiendo los resultados en un informe. Este reporte se presenta primero ante el Consejo; después solicita a la Junta de Gobernadores del BM que realice las recomendaciones en respuesta a la resolución del Panel. Finalmente, el Consejo de Directores Ejecutivos notifica las medidas aprobadas por la Junta de Gobernadores que deben tomarse como resultado del proceso de inspección.

Los requisitos de legitimidad para presentar una solicitud ante el $\mathrm{Pa}$ nel nos parecen de la mayor importancia, pues son propios de un procedimiento especial con cierto grado de complejidad técnica. En resumen son los siguientes: (i) que se cuente con dos o más personas con intereses o situaciones comunes viviendo en un país o región afectados por un proyecto financiado por el BM; (ii) que el BM haya violado sus políticas y procedimientos, que lleve a que dichas personas hayan sufrido o sean susceptible de sufrir daños y perjuicios; (iii) que dichas personas hayan presentado sus inconformidades ante el BM y no hayan sido satisfechas; (iv) que el proyecto esté bajo consideración o ya haya sido aprobado por el BM, y el préstamo aún no haya sido pagado sustancialmente. ${ }^{39}$

38 Véase Hansungule, M., "Access to Panel - The Notion of Affected Party, Issues of Collective and Material Interest", pp. 143 y ss.; Bissell, R., "Institutional and procedural aspects of the Inspection Panel”, p. 107; ambos en The Inspection Panel of the World Bank, cit.

39 Ha de tomarse en cuenta que el Panel tiene prohibido tramitar diversas categorías de solicitudes, entre ellas: (i) las relacionadas con acciones que sean responsabilidad de otras partes (como el gobierno del país en cuestión) y que no involucren acciones u omisiones del BM; (ii) las relativas a proveedores de productos o servicios relacionados con el proyecto; (iii) las referentes a proyectos financiados por la CFI o el OMGI, ya que estas dos últimas tienen un tratamiento procesal especial dentro del BM. 
Resulta interesante conocer que, si bien el grueso de las solicitudes de inspección están referidas a proyectos, el Panel también ha considerado peticiones relacionadas con créditos sobre ajustes estructurales de carácter general y sectorial que hayan ocasionado un daño. El crédito para el ajuste estructural de la crisis financiera de Argentina de 2001 es una buena ilustración de este criterio extendido de admisibilidad.

Como podrá advertirse, si bien el Panel de Inspección es un ente autónomo en sus investigaciones, dista sustancialmente de tener jurisdicción plena sobre el BM. En efecto, tanto la tramitación del asunto como las medidas consecuentes a la inspección están mediadas tanto por el Consejo de Directores Ejecutivos y el presidente, como por la Junta de Gobernadores del BM. Así, hay una serie de obstáculos políticos que el asunto debe ser capaz de sortear para ser efectivo. Más aún, incluso aspectos de carácter procesal básicos como los plazos a agostar son muy relativos y dependen de los vaivenes diplomáticos de los Estados Miembros y los órganos del BM. En este contexto de claroscuros, ¿cuál es la eficacia del Panel de Inspección? La respuesta no parece ser todavía suficientemente positiva.

Como ya se comentaba, el propósito fundamental del Panel se centra en la mejora de su operación y no en la indemnización de los afectados ni en la suspensión o cancelación de la obra financiada. En este sentido, se busca que la institución sea respetuosa de sus políticas y procedimientos a través de los resultados del mecanismo de inspección. Con esto se busca que los proyectos mejoren la calidad, se tengan lecciones para el futuro y se tomen acciones de responsabilidad interna.

Así pues, bajo nuestra óptica, si bien evidentemente el Panel no goza de facultades que trasciendan el ámbito de la operación interna del BM, debe considerarse como un punto en el camino, ya que naturalmente tendrá que evolucionar en el futuro hacia un ente con un nivel de autonomía mayor con ciertas facultades jurisdiccionales. Párrafos más adelante comentaremos algunas sugerencias académicas al respecto. Por lo pronto, nos parece que en él se experimenta ya una serie de cambios esperanzadores. Por ejemplo: (i) genera una participación ciudadana respecto a proyectos que inciden en la vida de las personas; (ii) facilitan la actividad de las ONG's como mecanismos de representación social; (iii) mejorar la operación y seguimiento de los proyectos; (iv) permite poner mayor énfasis en requerimientos ambientales y sociales. 
A la fecha, en sus cerca de veinte años de existencia, el Panel de Inspección ha recibido más de ochenta solicitudes relativas a casi cuarenta países, incluida una respecto a México relativa a un proyecto en el Istmo de Tehuantepec en 2004. ${ }^{40}$ Desde luego, no todas ellas han tenido la suerte de, además de cumplir con los requisitos formales de admisibilidad y ser objeto de inspección, sortear también los obstáculos políticos del BM, y llegar a una formulación de medidas correctivas por parte de la Junta de Gobernadores, como órgano máximo de la institución. En general, los casos se refieren a obras de infraestructura como hidroeléctricas, proyectos de administración de recursos naturales, puentes, sistemas de irrigación, etcétera. ${ }^{41}$

Con el fin de tener una muestra representativa de distintos renglones, veremos brevemente primero el caso de un proyecto hidroeléctrico en Nepal; después un crédito de ajuste sectorial en Bangladesh, y, por último, un proyecto de administración de recursos naturales en Brasil. Cada uno de ellos tiene particularidades propias que demuestran que, pese a sus limitaciones, el Panel de Inspección puede llegar a tener en el futuro una incidencia importante en la conciliación del ámbito financiero con valores propios de los derechos humanos y de la protección al ambiente.

El primer caso se refiere al proyecto de construcción de la Presa Arun III en Nepal registrado en el Panel a finales de 1994. A través de una solicitud, un grupo de ciudadanos nepalíes reclamó la falta de cumplimiento del BM con sus políticas sobre transparencia y acceso a la información, impacto ambiental, reubicación involuntaria y condiciones de los pueblos indígenas de la región. El proyecto estaba todavía en consideración y todavía no recibía financiamiento alguno del BM.

40 Si bien la solicitud de investigación por afectaciones ambientales, presentada por el comisariado ejidal de Ixtlán de Juárez en el Estado de Oaxaca fue hecha en 2004, a la fecha, la decisión sobre tramitar la investigación ha quedado diferida. Véase el micrositio de Panel de Inspección. Proyecto ID PO66674.

${ }^{41}$ Véase el estatus actual de cada uno de los asuntos planteados y registrados en el micrositio del Panel de Inspección (visita en junio de 2011) en www.worldbank.org. 
A partir de la recomendación del Panel, el Consejo autorizó proseguir con la investigación con respecto al impacto ambiental del proyecto; la reubicación involuntaria y el respeto a las poblaciones indígenas. Luego de la investigación, el Panel remitió al consejo su reporte, en donde se señalaba que de cumplir con una serie de sugerencias sobre cumplimiento de los estándares del BM el proyecto podría seguir su camino. A pesar de esto, una vez que el presidente del BM cambió, y tras un proceso de revisión integral, se decidió no seguir adelante con el financiamiento.

Desconocemos si esta decisión tuvo un elemento político propio de las instituciones financieras internacionales, o si en realidad el BM cayó en cuenta de su error al pretender financiar un proyecto que no cumplía con estándares sociales ni ambientales. Nos inclinamos por otorgar el beneficio de la duda, y concluir que probablemente el Panel mostró, pese a todas sus restricciones de autonomía, un nivel de eficacia razonable que motivó la decisión del presidente del BM a no seguir.

El caso de crédito para el ajuste sectorial de la industria del yute en Bangladesh fue incoado ante el Panel en 1996 por una serie de propietarios privados de ese país. En el caso se alegaba una serie de errores de diseño en el diseño e implementación del programa de ajuste, que a su vez ocasionó demoras y mayores incumplimientos por parte del gobierno contratante del crédito para cumplir las condiciones de éste.

A pesar de que el Panel consideró admisible el caso, no le pareció que una investigación fuera de utilidad alguna, toda vez que el nuevo gobierno de Bangladesh estaba ya negociando con el BM un nuevo calendario de implementación, que tomara en cuenta las demoras ya generadas. El Consejo aceptó, en este sentido, la recomendación del Panel de no seguir adelante con una investigación. Aunque el caso no parezca relevante por su falta de resultado práctico, lo cierto es que representa el primer caso sobre ajuste sectorial. Con lo cual abre la puerta a futuro, para una serie de supuestos equivalentes.

El caso del proyecto de administración de recursos naturales en Rondonia Brasil fue presentado en 1995 por un grupo de ONG's que actuaron en representación de residentes de la zona, en relación con el financiamiento para un proyecto que, desde su punto de vista, no cumplía con una serie de políticas del BM; entre las cuales están criterios 
ambientales de protección internacional de bosques, respeto a los pueblos indígenas y participación de ONG's.

Por la importancia del caso, la inspección no solamente fue admitida, sino que el propio Consejo requirió al Panel de mayor información sobre la especificidad de los daños ocasionados, y su relación con las desviaciones del proyecto de los estándares del BM. Luego de concluida esta segunda etapa y a partir de la formulación del Panel de un plan de medidas correctivas, el Consejo decidió no seguir con otras etapas de la investigación, sino apegarse a corregir en la medida de lo posible las desviaciones de estos estándares.

En este tercer caso, aunque no se hayan agotado todas las etapas del procedimiento, el efecto fue prácticamente el mismo. Con lo cual, el Panel parece un mecanismo flexible tendiente, cuando hay la voluntad política del Consejo, a ofrecer soluciones específicas sin demasiados trámites de procedimiento. Sin embargo, lo interesante del caso es el reconocimiento tanto del Panel como del Consejo, de la legitimidad en la representación de la sociedad civil por parte de ONG's.

4. Un alto en el camino: la situación del Panel de Inspección del BM y la necesidad de una reforma de diseño institucional a impulsar por el G20

A cerca de veinte años de su fundación y luego de varios proyectos evaluados y reportes emitidos, nos parece prudente hacer un alto en el camino y analizar si el Panel de Inspección requiere o no una reforma de diseño institucional a ser impulsada por el G20. Reforma que tenga como énfasis la prevención adecuada y la indemnización efectiva por daños causados a terceros, derivados de financiamientos del BM. Como hemos visto, el Panel claramente no es de modo alguno la panacea institucional que salvaguarde los derechos humanos y el desarrollo sustentable. ${ }^{42}$

${ }^{42}$ Véase Umana, A., "Some lesson from the Inspection Panel's Experience”, p. 127 y ss. Véanse, asimismo, dos experiencias comparadas en sistemas de inspección con cierto grado de autonomía en: McGill, E., “The Inspection Policy of the Asian Development Bank”, p. 191, 
En realidad, la pobreza de sus facultades jurisdiccionales y el poder que sobre ella ejercen los órganos políticos del BM hace que su autonomía real — sin menospreciar la independencia de sus miembros - sea cuestionable. Más aún, la falta de uniformidad y transparencia de sus procedimientos y plazos son un obstáculo a sus objetivos, y se ve todavía lejos el día que los afectados estén legitimados a ser indemnizados como en cualquier otro procedimiento que considere aspectos de responsabilidad civil.

A pesar de lo postulado sería injusto señalar que nada oportuno se ha hecho. En nuestra opinión, el acceso de la sociedad civil y de las ONG's; la admisibilidad de denuncias sobre proyectos y de programas de ajuste, así como la flexibilidad para llegar a soluciones prácticas son atributos positivos del Panel.

De este modo, como cualquier entidad viva, el Panel seguirá creciendo, y en su dinámica propia seguramente fortalecerá su autonomía, su jurisdicción y su eficacia tanto para mejorar proyectos crediticios futuros, como para resarcir a las víctimas de los daños generados. De cierto modo, la autonomía de facto, así como la aceptación por parte del Consejo del BM de todas las recomendaciones del Panel de Inspección, son una mejoría, pero no atacan el tema de raíz, que desde nuestro punto de vista es: el diseño institucional del Panel en el contexto de la responsabilidad de los organismos internacionales —el BM en este caso-frente a terceros perjudicados por proyectos financiados.

Diversos planteamientos de diseño institucional se han formulado con miras a mejorar la supervisión del Panel de Inspección respecto a las políticas crediticias y los proyectos específicos del BM. Entre ellos, destacan los estudios institucionales del Institut de Droit International (IDI)l, el de la International Law Association (ILA) y el de la International Law Commission (ILC). Todos ellos se han concentrado en la detección del problema sin verdaderamente profundizar en los cauces orgánicos de la solución. ${ }^{43}$

así como Miller, G., "The Independent Investigation Mechanism of the Inter-American Development Bank", p. 209; todos ellos en The Inspection Panel of the World Bank, cit.

43 Véase IDI Report, The Legal Consequences for Member States of the Non-Fulfilmet by International Organizations of their Obligations Toward third Parties, 1995; ILA Report; Accountability of International Organizations, 2004; ILC, Responsibility of International Organizations, 2007. 
Tal vez el planteamiento de mayor calado analítico y creativo ha sido el formulado por Andria Naudé. Con base en los principios necesarios de responsabilidad (accountability) y legitimación de las instituciones internacionales, y tras un estudio de cinco casos representativos en que los proyectos financiados por el BM generaron daños estructurales a comunidades y ambiente, la autora postula la necesidad de dotar al Panel de un auténtico espíritu judicial, a ser aprendido de los modelos judiciales nacionales, y no de instituciones internacionales. ${ }^{44}$

Es necesario advertir que de la agenda del G20 en el ámbito de los bancos multilaterales de desarrollo y el BM no se observa un punto detallado sobre la necesidad de reformar estructuralmente el Panel de Inspección, de modo tal que tenga un rol abiertamente judicial respecto a las políticas y proyectos financiados por el BM. En efecto, todo pareciera que el G20 se ha concentrado en la movilización de recursos financieros y el diseño de líneas de crédito diferenciadas para salir de la crisis de 2009 y contar con criterios preventivos de errores sistémicos en la economía global, asistido por el FMI.

Nos parece, sin embargo, que si bien la movilización de recursos ha sido — y es - una prioridad, no puede soslayarse la importancia de repensar el diseño institucional del Panel de Inspección con la mira tanto de prevención de proyectos como de análisis de situación tendiente a indemnizar a las víctimas de proyectos financiados por el BM.

\section{CONCLUSIONES}

La hipótesis de trabajo de este documento ha sido cómo, a pesar de que el G20 cuenta con una representatividad mundial incontrovertible, su legitimación en el rediseño de las instituciones financieras internacionales — FMI y BM- solamente puede darse en el ejercicio mismo de sus funciones.

${ }_{4}$ Véase Naudé Fourie, Andria, The World Bank Inspection Panel and Quasi-Judicial Oversight, Rotterdam, Países Bajos, Erasmus Universiteit Rotterdam, 2009, pp. 6 y ss. 
Esto es sólo la auténtica democratización de las entidades multilaterales, lograda a partir de la creatividad, profesionalismo - e incluso presión - de los líderes del G20, hará que el rol histórico al que está llamado a ocupar tras la crisis financiera 2008-2009 se convierta en un mérito loable. Para lograr tal democratización y revisión de objetivos y procesos, el G20 — incluida la poderosa China - está llamado a evaluar con amplitud de miras las recomendaciones de la Comisión de especialistas creada en la primavera de 2008 y encabezada por los profesores Stiglitz, Sen y Fitoussi.

En este contexto, para sugerir la demostración de la hipótesis de trabajo, hemos procurado examinar, en perspectiva, el surgimiento de las instituciones financieras internacionales en el ámbito del Sistema Bretton Woods de 1944, así como sus funciones primordiales y sus proyectos de desarrollo financiables.

En el corte temático de financiamiento para el desarrollo, hemos buscado particularizar tópicos ilustrativos — como el matiz de los instrumentos convencionales de derechos humanos y las necesarias mejoras del Panel de Inspección del BM - que, en su momento, formen parte de la agenda del G20 en su objetivo por un nuevo diseño institucional, en el cual la economía tenga auténticamente un rostro humano. 